\title{
Criminal Regulations on Child Abuse in China
}

\author{
Yue Cui ${ }^{1 *}$ \\ ${ }^{I}$ Qingdao No.2 Middle School of Shandong province, Qingdao,266000, China \\ *Corresponding author's Email: 2175601165@qq.com
}

\begin{abstract}
The abuse of children under the age of 14 by non-family members is a vacuum zone in the current criminal law. From the perspective of harmful consequences and social impact, even child abuse committed by non-family members is necessary to be criminalized. In the choice of the path of conviction, the new crime of child abuse and the expansion of the subject of the crime of abuse do not meet the requirements of the principles of criminal law. Based on the principle of limited formal interpretation, child abuse should be regulated through the crime of intentional injury, and through judicial interpretations, it is determined that child abuse does not have to follow the "minor injury" standard, and mental injury is also included.
\end{abstract}

Keywords: child abuse, the necessity of conviction, the crime of intentional harm, the principle of priority of formal interpretation

\section{INTRODUCTION}

In recent years, there have been frequent incidents of child abuse outside of family members, the social impact is bad, and the demand for severe punishment has been increasing. However, because my country does not stipulate the crime of child abuse, and the crime of abuse restricts the subject of behavior to family members, which leads to legal difficulties in the regulation of child abuse behavior, and faces huge difficulties in theory and judicial application. The nature of child abuse is bad, but it is difficult to get the punishment that it deserves, which has aroused widespread public concern and discussion. In view of this, it is necessary to discuss the theoretical disputes on the regulation of child abuse on the basis of a clear definition and analysis of the meaning of child abuse, including whether it should be regulated by criminal laws and the path of regulation, and on this basis The specific path for the regulation of child abuse behavior is put forward on the above.

\section{DEFINITION OF CHILD ABUSE}

According to the analysis of the word child abuse, "abuse" refers to cruel treatment, and "child" refers to children. Therefore, semantically speaking, child abuse includes all the rights and interests of children or the behavior of children themselves being cruelly treated.
Different scholars and organizations around the world have expressed different views and opinions on the definition of child abuse. The "Child Abuse Prevention Consultation Report" published by the World Health Organization in 1999 defines child abuse as "under certain responsibilities, trust or rights." Under the relationship, all forms of physical or emotional treatment, sexual abuse, neglect or negligence, commercial or other forms of exploitation that cause actual or potential harm to the health, survival, and dignity of children." Disease Control and Protection of the United States The Centers for Disease Control and Prevention defines "child abuse" as any behavior that causes harm, potential harm or intimidation to children. At the same time, the agency divides "child abuse" into four types: physical abuse, Sexual abuse, neglect, psychological and emotional abuse. In the United Kingdom's Children's Act promulgated in 1989, it is stipulated that any behavior that affects children's physiology, intelligence, emotions, and society is "child abuse." The above three definitions all reflect the broad meaning of "child abuse" in the concept of "child abuse", which not only includes physical abuse, but also emphasizes psychological and emotional abuse.

However, combined with the current legislative status of our country and the research reality of this article, the criminal law of our country has already regulated some behaviors in the broad definition of child abuse. In order to focus on the consideration of the behavior regulation that is not yet clear in the current 
law, the article described in this article The behavior of "child abuse" focuses on the behaviors that have not been included in the criminal law of our country, but still cause harm and social impact[1].

From the perspective of the degree of injury, if child abuse causes minor injuries or more, it can be dealt with through the crime of intentional homicide or intentional injury. For situations that have not caused minor injuries, if the subject is a family member, it can be dealt with through the crime of abuse in Article 260 of the Criminal Law. Therefore, those who have not yet been subject to criminal regulations are only implemented by non-family members and have not caused minor injuries or more of the consequences. In addition, based on the modest considerations of the criminal law, child abuse with significantly minor circumstances can also be dealt with through administrative punishment instead of using the criminal law. Of course, damage is not limited to physical and physical damage, but also includes mental oppression. However, it should be noted that sexual assaults against children also have special regulations for rape or indecent crimes, which are not included in the scope of harm referred to in this article. At the same time, because the preferential protection of children in my country's "Criminal Law" is mainly for minors under the age of 14 , based on the considerations consistent with the existing criminal law system, the child abuse behavior discussed in this article should also be set at the age of 14. age limit[2].

Therefore, the "child abuse" discussed in this article refers to the abuse of minors under the age of 14 by persons other than family members. Although it does not constitute minor injuries, it also causes greater harm or adverse effects. behavior.

\section{THE NECESSITY OF CRIMINALIZATION OF CHILD ABUSE}

Before discussing how the criminal law should regulate child abuse, we must first clarify a pre-existing theoretical issue, that is, the criminal law is indeed necessary to protect child abuse, and child abuse should be criminalized. The academic circles have different views on this issue. The negator believes that we must be vigilant about expanding interpretations. Behaviors that do not meet the existing elements of the criminal law should not be regulated by the criminal law, but should be treated as general violations. At the same time, some scholars also pointed out that it is unrealistic to blindly require the criminal law to punish all behaviors. Even if there are corresponding charges for regulation, based on the concealment of child abuse, it may also cause consequences that are difficult to effectively regulate [3]. Therefore, the fundamental strategy should be to strengthen pre-intervention, establish a monitoring and reporting mechanism, and introduce social organizations to jointly restrain.

It is true that the protection and restraint of the criminal law requires that the criminal law system must be prudent, and there are reasons for the argument that the criminal law should not be "kidnapped" by public opinion and oppose child abuse. However, the modest nature of the criminal law cannot be used as a universal excuse for rejecting the application of the criminal law. If an act should indeed be regulated by the criminal law, then even if it is not covered by the existing criminal law system, it should be included through law revision and interpretation. Otherwise, it will violate the basic requirements of criminal laws and regulations.

Going back to the fundamental point of criminal behavior under the criminal law, having a considerable degree of social harm is one of the conditions for the use of criminal law to resolve social conflicts. In other words, acts that have serious social harm or violations by law are criminally punishable. This standard reminds us that whether a certain behavior should be regulated by the criminal law is not determined by the existing criminal law, but should be weighed against social harm or infringement of legal interests. It must be admitted that the lagging nature of the law will bring about the weakness of existing legal norms that are difficult to keep up with social development and progress. Therefore, it is undesirable conservatism to blindly follow the existing regulations and refuse to seek the upgrade and change of the norms. If a certain behavior is of great social harm, but cannot be subject to criminal regulations because it abides by the provisions of the criminal law, it will bring irreparable consequences.

After clarifying the criterion of social harm, it is necessary to examine the issue of whether child abuse should be criminalized. It should be said that the social harm or legal interest infringement of child abuse is very serious and criminally punishable. First, child abuse seriously violates children's right to health. Although the conviction standard for the crime of intentional injury is minor injury, this standard is determined for the general situation of adults, and the situation of children is different from that of adults. Children's bodies are still in the growth and development stage, and various body functions are still in the growth stage. If they are severely stimulated by the external environment, the possibility and degree of damage will be more serious than adults. Therefore, it is unreasonable to judge the degree of injury of a child based on the adult standard of minor injury. Second, child abuse has seriously violated children's mental health. In addition to physical injury, children are also more vulnerable to psychological injury than adults, and may cause serious consequences. Studies have shown that compared with physical harm, child abuse causes more serious psychological harm to children, and the 
impact is longer[4]. Psychological injury will not only cause great damage to children's personality and dignity, and cause children to suffer major mental trauma, but also cause many adverse effects on children's personality and social adaptability, leading to borderline personality disorder and trauma. Serious mental problems such as post-mood disorder will often cause more serious consequences. At the same time, as a group that both the legal system and the entire society agree that protection must be favored, the social impact of their injuries is different from that of adults. As the hope of the family, the social impact caused by the injury of children will be greater and the situation will be even worse. It can also be seen from the public opinion caused by child abuse that has continued to appear in recent years that society has shown significantly more resentment towards child abuse. Therefore, considering that child abuse has caused great physical and psychological harm to children, as well as the more serious social consequences that child abuse may bring. It is necessary to criminalize child abuse [5].

In addition to meeting the standard of social harm, the criminalization of child abuse is still a requirement for the perfection of the criminal law system.

From the perspective of maintaining the integrity of the criminal law system, child abuse should also be criminalized. Compared with the crime of abuse stipulated in Article 260 of China's "Criminal Law", child abuse is more harmful to society and has worse social impact, so it should be subject to criminal laws and regulations. The abuse in the crime of abuse generally occurs between family members with relatives, and it is mainly due to an "education" mentality. Since ancient times, our country has the tradition of "filial piety under a stick", and traditional concepts also believe that it is right. Children's beating and scolding is a normal way of education, and children should be allowed to grow up in the process of beating and scolding. The legislators obviously took into consideration our country's traditional concepts and family relationships, so they stipulated that the crime of abuse should be dealt with only when it is required to be notified. The child abuse behaviors that occur in kindergartens or nurseries not only lack the essential attributes of education and care, but often punishment and pleasure occupy the main mentality. A typical example is that Yan, the abuser in the Wenling case, bluntly expressed her mentality in an interview. She said that her purpose of raising the children's ears instantly was mainly for taking pictures for fun, and there was no think too much. Another example is the behavior of kindergarten teachers in Jiading District, Shanghai who scratched children with scissors. It is far-fetched to be educational or to think that the implementer is educational. In a sense, the damage to the physical and mental health of children caused by this kind of child abuse is more serious than the violation of legal interests caused by the crime of abuse, and the abuse of children by teachers is more condemnable than the abuse of children by parents. It is easier to arouse the anger of the public. Therefore, if the criminal law only provides for less socially harmful family child abuse, but does not deal with more socially harmful social child abuse, it is obviously inappropriate. Although there are no existing direct charges that can be applied to child abuse, we should also follow the spirit of the principle of prudence, and from the perspective of criminal law interpretation, seek a suitable crime for consideration of child behavior to regulate, rather than essentially Deny the criminal punishability of child abuse.

From the point of view of criminal policy, child treatment is also necessary to be convicted. The criminal policy of both leniency and strictness is a basic criminal policy currently in our country. This criminal policy requires "leniency and strictness, both leniency and strictness, and both leniency and strictness". It is not blindly decriminalization or mitigation of penalties that is the implementation of the combination of leniency and strictness. As mentioned earlier, child abuse is a more serious social hazard behavior than the crime of abuse, and criminalizing it exactly reflects the basic spirit of the criminal policy of tempering justice with mercy. In addition, strengthening the protection of the physical and mental health of minors, especially children, has always been a social policy and criminal policy of our country. If it is said that the criminal law is suspected of being absent due to the lack of intuitive and directly applicable crimes against child abuse, then from the judicial level, it should be based on the purpose of implementing China's criminal policy to protect minors, and focus on the treatment of child abuse. The necessity of conviction of child behavior, and seek suitable crimes to be regulated through the path of interpretation. If China's Constitution, the Law on the Protection of Minors, and the Law on Compulsory Education all advocate the effective protection of children's rights and interests, but because they do not have the ultimate protection of the criminal law, these laws have become "a dead letter", which is obviously not the original intention of the legislators. In order to avoid this embarrassing situation, we must first affirm the necessity of criminalizing child abuse, and then find another way to find a way to sin. In any case, with regard to child abuse, we should adopt the regulation of the former law to the guarantee of the latter law, engage in pre-prevention, intervene in the incident to disciplinary action after the incident, and establish a pluralism from the family, school to public institutions, society and the country. Governance of child rights protection net. This kind of multi-faceted protection net obviously must include the net of criminal law, otherwise the protection means will be incomplete and the protection effect will not be achieved. 
In summary, whether it is based on the standards of social harm or the requirements of the perfection of the criminal law system, the crime of child abuse is included in the scope of the criminal law, and the criminal penalties of child abuse have a solid theoretical basis.

\section{THE PATH CHOICE FOR THE CRIMINALIZATION OF CHILD ABUSE}

The preceding article confirms the necessity of convicting child abuse, so what needs to be discussed next is how to convict child abuse. There is no shortage of scholars' views on the theory of conviction in academia, but the paths of conviction are different. Some scholars believe that my country's criminal law should add the crime of child abuse, and some scholars believe that the interpretation of the crime of abuse should be passed. Expand the main body of the crime of abuse, so as to realize the incorporation of child abuse into the criminal law system.

Regarding the first point of view, that is to add the crime of child abuse to the existing criminal law system, some scholars believe that the crime of child abuse is very common in the legal systems of other countries. Child crime. However, adding a new crime is not an easy task. It is hoped that there are many problems in the regulation of child abuse through the addition of child abuse. First, the addition of the crime of child abuse may lead to an over-expansion of the criminal law guilt system, which may lead to chaos. If there are any gaps in the criminal law system in the future, new accusations are advocated, it will inevitably lead to the continuous increase in the number of criminal accusations and the continuous expansion of the accusation system. New crimes must be very rigorous. After many arguments, blindly adding new crimes before demonstrating whether other methods are feasible does not meet the requirements of minimization. Secondly, before the criminal law is amended, if it can be solved by the method of criminal law interpretation, then the principle of priority of criminal law interpretation should be adhered to. The criminal law can be amended only when there is no way to regulate harmful behaviors no matter how the interpretation is or it can only be achieved through unreasonable interpretation methods. Moreover, the newly established crime of child abuse partially overlaps with the existing crime of abuse. Although the subject is indeed distinguished, it will trigger a discussion on the validity of such a distinction and a discussion on whether the two crimes should be combined. Bring more hidden problems.

Regarding the second point of view, expanding the subject scope of the crime of abuse, that is, expanding the concept of family members to include non-family members through an explanatory method, so as to achieve the goal of including child abuse in the crime of abuse regulation. The core of this approach is to interpret non-family members as de facto family members. The reason is that kindergarten teachers and similar professions have guardianship obligations equivalent to family members, and kindergarten teachers have de facto guardianship for children. However, this interpretation path is a typical expanded interpretation. Family member relationships have specific meanings and require kinship based on blood, in-laws, or adoption relationships that have mutual support obligations[6]. Although kindergarten teachers can be interpreted as having a formal guardianship obligation, this obligation is based on an equal contractual relationship, and it is difficult to interpret it into the three situations of family relationship formation. Such an expanded interpretation violates the basic requirements of criminal law interpretation and may fall into the trap of "presumption of guilt". In addition, not all child abuse by non-family members can be expanded to explain like kindergarten teachers. If it is the case of care without a contract, it cannot be regulated through this expanded explanation.

Therefore, whether it is to add the crime of child abuse or expand the subject scope of the crime of abuse, it does not meet the requirements of the principles of criminal law, and other reasonable approaches must be sought. Based on the principle of priority in criminal law interpretation, this article believes that child abuse should be regulated through the crime of intentional harm.

According to the cited case, the behavior of the perpetrators slapped the face, lifted the child's ears momentarily, or scratched the child's arm with stationery scissors are all harmful behaviors aimed at the child's body. These behaviors carried out by the perpetrator have exceeded the scope of normal discipline. Therefore, child-care behavior is essentially a harmful behavior that illegally damages the health of others. In this way, it is worthwhile to focus on the question of whether the legal interests of child abuse and the crime of intentional injury are consistent, that is, whether the right to physical health violated by the crime of intentional injury includes the right to mental health. As mentioned earlier, child abuse mainly infringes on children's right to physical and mental health, and whether the legal benefits of the crime of intentional injury include the right to physical and mental health is still controversial. Some scholars believe that the legal benefit of the crime of intentional injury is the health of a person's physical function, not the health of the mental state. In other words, the conviction of the crime of intentional injury is based on causing damage to a person's physiological function. But this view is debatable. The legal benefit of injury crime protection refers to the personal legal benefit, including the integrity of the body and the inviolability 
of the body, the key to the physical function and the health of the mental state. This should be the proper meaning of the body's legal benefits. However, if it is an act that slightly damages the physical integrity or inviolability of the form, such as cutting off hair or nails, it is not considered a crime because the circumstances are significantly minor. Of course, the fact that the criminal law does not consider it to be a crime does not mean that this is an act worth encouraging. In addition, the health of physiological function and the health of mental state should be sideby-side physical benefits, and the two should not be conflated. The legislative purpose of the crime of injury is to protect the integrity of the body. The integrity of the body not only refers to the integrity of the body, but also refers to the normal state of mind. Therefore, we cannot deny the objective existence of psychological or mental damage because of the difficulty of identification, especially when the object of the infringement is a child, the damage to the mental health of the behavior may even be more serious than the damage to the physical function. Moreover, China's criminal law does not stipulate that the crime of intentional injury must be slightly injured. In this sense, China's general position has no legal basis.

The "minor injury and above" standard mentioned above for the crime of intentional injury is not reflected in the provisions of the criminal law, but only a general or trial consensus, rather than a necessary constituent element fixed in the legal provisions. The main reason for the formation of this general theory is that for deliberate injury of adults, the standard of minor injury can indeed distinguish the severity of the infringement of legal interests and maintain the modest nature of the criminal law. However, as mentioned above, the degree of harm received by children in child abuse cannot be measured by the standard of ordinary adults, and the identification of minor injuries cannot be completely based on the fixed standards of adults. At the same time, the general theory of "minor injury standards" is inherently faced with the problem of only attaching importance to physical injury and neglecting mental injury. Although mental injury is relatively difficult to prove and concealed, based on the standards of legal interest infringement and social adverse effects, the possible serious consequences of mental injury to children must require mental injury to be included in the category of intentional injury. Therefore, the caliber of this trial should be adjusted accordingly. Of course, based on the principle of minimum change, it is not necessary to modify the criminal law provisions. It can be confirmed through judicial interpretation that it is not necessary to require "minor injuries or more" when a child receives injuries, and it is emphasized that mental injuries should also be included in the same way as physical injuries. The basis of the crime. At the same time, the corresponding identification standards for mental injury should be further improved, and a complete injury identification process should be gradually established.

\section{CONCLUSION}

The abuse of children under the age of 14 by nonfamily members is a vacuum zone in the current criminal law. From the perspective of harmful consequences and social impact, even child abuse committed by non-family members is necessary to be criminalized. In the choice of the path of conviction, the new crime of child abuse and the expansion of the subject of the crime of abuse do not meet the requirements of the principles of criminal law. Based on the principle of limited formal interpretation, child abuse should be regulated through the crime of intentional injury, and through judicial interpretations, it is determined that child abuse does not have to follow the "minor injury" standard, and mental injury is also included. Of course, it is far from enough to regulate child abuse by perfecting the criminal law. It is necessary to strengthen prior intervention and strengthen the joint supervision of government agencies and social organizations to establish a safe environment for children's growth and truly ensure the healthy growth of children.

\section{REFERENCES}

[1] H. Mingru, X. Xiating, Incrimination of child abuse behavior and its resolution, Journal of Xiangtan University(Philosophy and Social Science), 2013, 37(5), pp. 7-13.

[2] L. Xianquan, W. Zhou, The proper way to deal with child abuse from the perspective of criminal law, Juvenile Delinquency, 2013, (1). pp.6-12.

[3] S. Ling, L. Ning, Criminal Law Analysis of "Child Abuse Cases": From the Perspective of the Application of the Crime of Abuse, People Tribune, 2014, pp.133-135.

[4] H. Jian, On the Criminal Law Regulation of "Child Abuse", China Criminal Law Miscellaneous, 2013, (2), pp. 49-56.

[5] L. Wenjun, The Predicament of Criminal Regulation on Child Maltreatment and its Solution, Youth Studies, 2015, (2), pp. 58-65.

[6] S. Yunliang, "Atrocity crimes" should be established in the criminal law of our country: Centering on the criminal law system of child abuse, Science of Law (Journal of Northwest University of Political Science and Law), 2013, (3), 75-83. 